\title{
Limbic encephalitis with DPP6 antibodies
}

INSERM

\section{Source}

INSERM. (1999). Orphanet: an online rare disease and orphan drug data base. Limbic encephalitis with DPP6 antibodies. ORPHA:329341

Limbic encephalitis with DPP6 antibodies is a rare brain inflammatory disease characterized by subacute or insidious onset of variable neurological features including cognitive dysfunction (memory impairment, hallucinations, confusion, amnesia), central hyperexcitability (agitation, tremor, myoclonus, exaggerated startle), brain stem involvement (dysphagia, dysarthia, ataxia) and disturbed sleep. Symptoms of dysautonomia include diarrhea, gastroparesis, and constipation. 